\section{Rhabdomyolysis due to combined treatment with lovastatin and cholestyramine}

Assistant Professor C ChrysanthoPoulos (Patras Medical School, Patras, Greece) and Professor Nicholas Kounis (Patras Technological Educational Institute Patras 26221, Greece) write: We report two cases in which rhabdomyolysis occurred after combined treatment with lovastatin and cholestyramine.

Case 1-A 31 year old male athlete with type IIa hyperlipidaemia was treated with lovastatin $20 \mathrm{mg}$ twice daily and cholestyramine $12 \mathrm{~g}$ twice daily. Four weeks later he experienced diffuse muscular pain and generalised weakness and was unable to walk. Clinical examination showed sluggish tendon reflexes and diffuse muscle tenderness. His urine was red-brown, and dipstick testing showed high concentrations of haem Microscopic examination of urine showed four to eight erythrocytes per high power field and urine myoglobin concentration was $125000 \mu \mathrm{g} / \mathrm{l}$. Serum muscle enzyme concentrations were raised (serum myoglobin $>200 \mu \mathrm{g} / \mathrm{l}$ ), but his renal function remained normal. Drug treatment was stopped, and he was confined to bed and treated with intravenous fluids. Twenty four hours later the myoglobinuria had resolved. The muscle pain and weakness resolved gradually over the next two weeks, and the serum muscle enzyme concentrations returned to normal.

Case 2-A 42 year old man with type IIa hyperlipidaemia had persistently raised serum lipid concentrations despite appropriate die and drug treatments. $\mathrm{He}$ took regular aerobic exercise. His blood urea concentration was $6.7 \mathrm{mmol} / \mathrm{l}$ and serum creatinine $88 \mu \mathrm{mol} / \mathrm{l}$. Lovastatin $20 \mathrm{mg}$ twice daily and cholestyramine $12 \mathrm{~g}$ twice daily were started. Two weeks later he experienced aching of his muscles, which gradually worsened, leading to generalised tenderness and weakness. The urine was dark, and dipstick testing showed high concentrations of haem. The urine myoglobin concentration was $115000 \mu \mathrm{g} / \mathrm{l}$. Serum muscle enzyme concentrations were increased (serum myoglobin $>250 \mu \mathrm{g} / \mathrm{l}$ ), and renal function was impaired (ure $26 \mathrm{mmol} / \mathrm{l}$, creatinine $400 \mu \mathrm{mol} / \mathrm{l}$ ). Drug treatment was stopped, the patient was confined to bed, and haemodialysis was started the next day. This treatment was continued for two months until the laboratory findings returned to normal.

Severe but reversible myopathy has been reported in two patients receiving combined treatment with lovastatin and cholestyramine and in one patient receiving lovastatin alone. ${ }^{12}$ There are at least four reports of rhabdomyolysis and acute renal failure and three of rhabdomyolysis without renal failure in patients undergoing cardiac transplantation receiving both lovastatin and cyclosporin..$^{3.5}$ Rhabdomyolysis and renal failure have been reported in seven patients receiving combined treatment with lovastatin and gemfibrozil of whom three had pre-existing renal impairment. . $^{6-8}$

Lovastatin probably interferes with muscle metabolism. Both ou patients took regular aerobic exercise. Myoglobinuria may be caused by vigorous exercise, and evidence suggests that exercise predisposes to myopathy. ${ }^{2}$ We cannot say whether cholestyramine played a part in the development of rhabdomyolysis, which should therefore be attributed to lovastatin and exercise alone.

All patients receiving lovastatin alone or with other drugs should avoid strenuous muscular work and be monitored for muscular symptoms.

1 Maher VMG, Pappu A, Illingworth DR Thompson GR. Plasma mevalonate respon in lovastatin-related myopathy. Lancet 1989 ; ii: 1098 .

2 Walrvens PA, Greene C, Frerman FE. Lovastatin, isoprenes, and myopathy. Lance 1989;ii: 1097-8.

Corpier $\mathrm{CL}$, Jones $\mathrm{PH}$, Suki $\mathrm{WN}$, Ledere MD, Quinones MA, Schmidt S, et al. Rhabdomyolysis and renal iniury with lovasdotin use: report of two cases in cardiac transplant recipients. FAMA 1988;260: 239-41.

4 Norman DJ, Illingworth DR, Munson J, Hosenpud J, Myolysis and acute renal failure in a heart-transplant patient receiving lovastatin. $N$ Engl f Med 1988;318:46-7.

East C, Alivizatos PA, Grundy SM, Jones $\mathrm{PH}$, Farmer JA. Rhabdomyolysis in patients receiving lovastatin after cardiac tran plantation. $N$ Engl f Med 1988;318:47-8.

6 Kogan AD, Orenstein S. Lovastatin-induced thabdomyolysis. Postgrad Med f 1990;66: 294-6.

Marais GE, Larson KK. Rhabdomyolysis and acute renal failure induced by combination lovastatin and gemfibrozil therapy. Ann Intern Med 1990;112:228-30.

8 Pierce LR, Wysowski DK, Gross TP. Myopathy and rhabdomyolysis associated with therapy. IAMA 1990;264:71-5.

\section{Nifedipine induced gingival abscesses}

Drs Gabriela Koller-Benz, ANDREA Fritzsche, and Reto KRAPF (Insel University Hospital, CH-3010 Berne, Switzerland) write: The calcium channel blocking drug nifedipine has been implicated in the development of gingival hyperplasia..$^{1-3}$ Here we describe a woman who developed gingival abscesses after taking nifedipine.

Three days after starting nifedipine ( $10 \mathrm{mg}$ four times a day) for idiopathic Raynaud's phenomenon a 27 year old woman consulted a dentist with three gingival abscesses. While she continued to take nifedipine five more abscesses appeared over the next two days. The abscesses were drained by a paradontologist and nifedipine stopped. Three weeks later her gingiva was normal. We restarted the patient on nifedipine at the same dosage. After two weeks she developed a large gingival absces and stopped taking nifedipine; two days later the abscess was drained. Biopsy of the abscess wall showed pronounced lymphoplasmacellular infiltrates. There was no epithelial hyperplasia or increase in acid mucopolysaccharide concentration (alcian blue staining), and no bacteria or fungiwere present in the specimen. No organisms other than Streptococcus viridans were cultivated in the drained material. The abscess healed uneventfully and the patient had no further gingival or dental problems after discontinuing nifedipine treatment (follow up seven months).

The temporal association and recurrence on re-exposure suggest that nifedipine was responsible for the development of gingival abscesses in this patient. She was taking no other drugs and we later confirmed that she swallowed the nifedipine and did not hold it in her mouth. The clinical and histological characteristics were different from the gingival hyperplasia previously observed in patients taking nifedipine, which is characterised by epithelial hyperplasia, absence of serious inflammation, and an increase in acid mucopolysaccharide concentrations..$^{1-3}$ Nifedipine should be stopped in a patient with gingival abscesses; discontinuation may eliminate the need for surgical intervention.

1 Lucas RM, Howell LP, Wall BA. Nifedipineinduced gingival hyperplasia. $f$ Periodonto 1985;56:211-5.

2. Van der Wall EE, Tuinzing DB, Hes J. Gingival hyperplasia induced by nifedipine, an arterial vasodilating drug. Oral Surg Oral an arterial vasodilating drug. Orat $1985 ; 60: 38-40$.

3 Shaftic AA, Widdup LL, Abate MA, Jacknowitz AI. Nifedipine-induced gingiva hyperplasia. Drug Intell Clin Pharm 1986;20:602-5

Guillain-Barré syndrome after treatment with streptokinase

Dr D BARNes and Professor R A C HUGHES (Guy's Hospital, London SE1 9RT) write: A few reports have implicated intravenous streptokinase as a precipitant of the Guillain-Barre syndrome. ${ }^{1.3}$ We have recently seen such a case. A 45 year old epileptic man suffered a myocardial infarction in January 1991 and was treated with intravenous streptokinase. He made an uneventful recovery, but three weeks later he noticed pins and needles in his hands and feet and bilateral facial weakness. $\mathrm{He}$ also

suffered his first seizure for 10 years and was readmitted to hospital. Over one week his condition progressed to a glove and stocking sensory loss, severe leg and bulbar weakness, moderate arm weakness, and bilateral internuclear ophthalmoplegia. The results of routine investigations, including a porphyrin screen and viral antibody titres, were normal. The protein content of cerebrospinal fluid was greater than $2 \mathrm{~g} / \mathrm{l}$ with no white cells. Motor conduction velocities were slightly slowed $(41 \mathrm{~m} / \mathrm{s}$ in the forearm segment of the median nerve; $29 \mathrm{~m} / \mathrm{s}$ in the leg segment of the tibial nerve), distally evoked motor action potentials were small and dispersed, and $F$ waves were unobtainable. These findings suggested a demyelinating neuropathy. He was given six plasm exchanges, during which his neurological condition improved. One month after the onset of symptoms power in his arms had returned to normal and he could walk with a frame. After three months he was walking independently.

Only two cases of the GuillainBarré syndrome occurring after myocardial infarction not treated by streptokinase have been reported. Since myocardial infarction is common this association was probably coincidental. Five cases of the Guillain-Barré syndrome after steptokinase treatment have been described, including ours, but only two occurred after myocardial infarction ${ }^{1}$; the other indications fo streptokinase were axillary vein thrombosis and multiple pulmonary emboli, and the indications were no stated in the third case.$^{23}$ It remain unclear whether this association genuine or coincidental. ${ }^{5}$ Only on such case was recognised in each of 1981, 1982, and 1983 despite doubling in the annual number of patients treated with streptokinase during this period. In the United Kingdom the Committee on Safety of Medicines has not received any other similar reports. As streptokinase is a foreign protein derived from group $\mathrm{C}$ streptococci it might induce the immunological reaction that is presumed necessary for the development of the Guillain-Barré syndrome.

Leaf DA, MacDonald I, Kliks B, Wilson R, Jones SR. Streptokinase and the GuillainJarré syndrome. Ann Intern Med 1984;100: 